\title{
Relationship between Peer Victimization, Personal Growth Initiative and Perceived Social Support
}

\author{
Ms. Shraddha $\mathrm{Pol}^{1}$, Ms. Jennifer Chandani ${ }^{2}$
}

\section{ABSTRACT}

Peer victimization includes being bullied and experiences of being the target of physical, social, emotional, or psychological harm from a peer. Personal growth initiative is an individual's will to change, develop and evolve as a person. Perceived social support refers to how an individual perceives the support or the encouragement that he gets from his/her society, friends and others. Thus, the purpose of this research was to study the relationship between Peer victimization, Personal growth initiative (PGI) and Perceived social support among adolescents. The population for this study consisted of 100 participants, males and females both between the age range of 13-19 years. The statistical analysis used was Pearson's product moment correlation. The findings revealed significant negative relationship between Peer Victimization and Personal Growth Initiative $(r=-0.31, p<0.01)$ and a significant positive relationship between Personal Growth Initiative and Perceived Social Support $(\mathrm{r}=0.50, \mathrm{p}<0.01)$. However, no significant relationship was found between Peer Victimization and Perceived Social Support. $(r=-0.18, n . s)$.

Keywords: Adolescence, Peer victimization, Personal growth initiative, Perceived social support

Adolescence can be defined as the period following the onset of puberty during which a young person develops from a child into an adult. From its beginnings at the turn of the century, the scientific study of adolescent development has always had as part of its implicit and explicit agendas the goal of describing, explaining, predicting, and ameliorating problematic behaviour.

Adolescence has long been characterized as a time when individuals begin to explore and examine psychological characteristics of the self in order to discover who they really are, and

\footnotetext{
${ }^{1}$ Former Post-Graduate student of Psychology, MMP Shah Women's college of Arts and Commerce, SNDT Women's University, Mumbai, India

${ }^{2}$ Former Assistant Professor at MMP Shah Women's college of Arts and Commerce, SNDT Women's University, Mumbai, India

*Responding Author
}

Received: July 4, 2018; Revision Received: August 24, 2018; Accepted: September 1, 2018 
how they fit in the social world in which they live. During the transition into adolescence, however, adolescents spend increasing amounts of time alone and with friends, and there is a dramatic drop in time adolescents spend with their parents (Larson \& Richards 1991).

Adolescents choose friends with similar behaviours, attitudes, and identities (Hogue \& Steinberg 1995). Finally, susceptibility to peer influence is not uniform among adolescents. Factors such as adolescents' age, personality, socialization history, and perceptions of peers are all important to consider. Adolescents are most influenced by peers in middle adolescence, compared to early and late adolescence (Brown, 1990).

Peer victimization also commonly labeled harassment or bullying - as physical, verbal, or psychological abuse of victims by perpetrators who intend to cause them harm is associated with multiple aspects of psychosocial functioning, including anxiety, depressive symptoms, loneliness, and low self-esteem.

Bullying can occur anywhere; some of the most common reported places being schools, the workplace, and even within one's own family. With the increase of public awareness of the prevalence and the harmfulness of bullying behavior, there has also been a rise in the alarm that public feels towards it. Olweus, a leading investigator in the field, defined bullying as aggressive behavior with the intent to harm another person. Bullying occurs intentionally and persistently over time, and in relationships characterized by an imbalance of power. Bullying usually takes one of three forms: (i) direct bullying which includes verbal or physical aggression toward another, (ii) indirect bullying includes using social relationships to harm the victim e.g., gossiping and spreading rumors, and intentional isolation, and (iii) cyberbullying that occurs via electronic communication through internet, phone, or social media. (Olweus, 1993). Bullies are described as aggressive, disruptive, likely to start fights, while simultaneously displaying less cooperative behavior and lower self-esteem.

Personal Growth Initiative (PGI) can be described as: "the intentional and active desire to grow in areas that are salient for a person” (Robitschek, 1998; Robitschek et al., 2009). PGI consists of general skills for personal growth. Moreover, these skills are transferable to different growth opportunities and life stages (Robitschek, 1999; Robitschek \&Kashubeck, 1999). Personal growth initiative, a construct operationalized by Christine Robitschek, is intentional engagement in the process of trying to change oneself.

Personal growth initiative has been related to a broad range of dimensions of human functioning, including both adaptive and maladaptive functioning. People with high levels of personal growth initiative also tend to have high levels of adaptive coping skills, specifically a reflective coping style. They are better able to cope with transitions in life because they know how to make changes in themselves.

Perceived social support is the perception and actuality that one is cared for, has assistance available from other people and that one is part of a supportive social network. These 
supportive resources can be emotional (e.g., nurturance), tangible (e.g., financial assistance), informational (e.g., advice), or companionship (e.g., sense of belonging) and intangible (e.g., personal advice). Social support can be measured as the perception that one has assistance available, the actual received assistance, or the degree to which a person is integrated in a social network. Support can come from many sources, such as family, friends, pets, neighbours, co-workers and organizations.

Perceived social support refers to a person's perception of readily available support from friends, family, and others. It also shows the complex nature of social support including both the history of the relationship with the individual who provides the supportive behaviour and the environmental context (Hobfoll\& Vaux, 1993).

The present study was formulated as an effort to identify significant correlations between the variables. There are three variables in this study: Peer victimization, personal growth initiative and perceived social support.

\section{Aim}

- To find out the relationship between Peer Victimization, Personal Growth Initiative (PGI) and Perceived Social Support among adolescents.

\section{REVIEW OF LITERATURE}

There have been many researches on peer victimization and social support. Today's generation is facing a lot of problems concerning the bullying or victimization which they face in their school premises. While some individuals after being victimized, receive the much needed support from their family, friends and significant others, most individuals do not.

The study conducted by Megan M. Muchicko, Andrew Lepp \& Jacob E. (2015) put some light on the relation between peer victimization, social support and leisure-time physical activity in transgender and cisgender individuals. The study stated that, Transgender individuals were less physically active and reported lower social support and physical selfperception than their cisgender peers. Social support and self-perception emerged as mediators of the difference in physical activity between transgender and cisgender individuals' Social support and self-perception emerged as mediators of the difference in physical activity between transgender and cisgender individuals. Results highlight the need for inclusive leisure settings and programs as well as increased social support for transgender individuals to maximize leisure-time physical activity. (Megan M. Muchicko, 2015)

Benoît Galand, Virginie Hospel (2012) tried to study the concept of Peer victimization and school disaffection: Exploring the moderation effect of social support and the mediation effect of depression. The study emphasized that, Peer victimization was negatively associated with self-efficacy and positively associated with school disaffection. No significant interactions emerged between victimization and social support or between sources of social 
support. Effects of victimization on self-efficacy and school disaffection were fully mediated by depression, but that the effects of social support are partially independent of depression. (Benoît Galand, 2012)

A study done by Prahbhjot Malhi, Bhavneet Bharti and Manjit Sidhu on Peer Victimization (relational and physical) on Indian adolescents indicated that, Physical bullying was reported by $8 \%$, relational bullying by $12 \%$, and $4 \%$ reported being victims of both physical and relational bullying be victims of relational bullying. Victims of relational aggression had relatively higher depression scores and conduct problems, while physically victimized adolescents reported more peer problems. (Prahbhjot Malhi, 2015)

Helena Martin in the year 2009 conducted a study on Personal Growth Initiative as a Moderator of the Outcome of Expressive Writing Tasks: Test of a Matching Hypothesis. This study explored whether participants differ in the extent to which they profit from two different versions of expressive writing depending on whether they are high or low on the personality dimension of personal growth initiative (PGI). The researcher found that, overall, those lower in PGI found greater benefit from the traditional writing task than the BPS task. In contrast, those higher in PGI found greater benefit from the BPS task than the traditional writing task. (Martin, 2009)

Perceived social support, hope, and quality of life of persons living with HIV/AIDS: a case study from Nepal was a study done by Sushil Yadav in the year 2010. A cross-sectional in design was applied, among a sample of $160 \mathrm{HIV}$-infected persons receiving treatment, care, and support from eight community-based NGOs. The study said that, Overall satisfaction from social support and hope was significantly correlated with QOL; the greatest effect of social support was on environmental functioning, and the lowest was on social relationships, emotional support was less a predictor of social relationship than other types of supports. (Yadav, 2010)

The research questions for the study are -

1. Is there a relationship between Peer Victimization and Personal Growth Initiative among adolescents?

2. Is there a relationship between Personal Growth Initiative and Perceived Social Support among adolescents faced with peer victimization?

3. Is there a relationship between Peer Victimization and Perceived Social Support?

\section{METHODOLOGY}

\section{Participants}

The sample size for the research was100. The sample consisted of adolescents (both males and females) with age group of 13 to 19 years from the city of Mumbai including the central and suburban areas. All participants had at least seven years of formal education. A method of convenience sampling was used. Vernacular medium students and students outside of 
Mumbai were not included. For the purpose of data collection a method of convenience sampling was used.

\section{Variables}

Peer victimization, Personal growth initiative and Perceived social support.

Tools

\section{The Multidimensional Peer Victimization Scale:}

The Multidimensional Peer Victimization Scale will be used to measure the victimization faced by adolescents. It is a self-report measure, designed to assess four types of peer victimization (social manipulation, attacks on property, verbal victimization, and physical victimization). Created by Mynard, H. \&amp; Joseph, S. (2000). The scale has good reliability and validity. (Internal reliability for each subscale: Physical victimization $=0.85$, verbal victimization $=0.75$, social manipulation $=0.77$, property attacks $=0.73$ ). The scale is a 3 point likert type scale ranging from 0 to 2 where 0 being not at all to 2 being more than once.

\section{The Personal Growth Initiative Scale II:}

The personal growth initiative scale will be used to assess the adolescent's will to change, develop and evolve as a person. The PGIS-II is a revised multidimensional measure of the complex processes of personal growth initiative. The Personal Growth Initiative Scale-II (PGIS-II) included 4 subscales: Readiness for Change, Planfulness, Using Resources, and Intentional Behavior. A study into the psychometric evaluation of the PGIS- II (Robitschek et al., 2012) provided an exploratory and confirmatory evidence for the 4- factor structure, strong internal consistency for the subscales and overall score across samples, acceptable temporal stability at all assessed intervals, and concurrent and discriminant validity of the PGIS-II. This is a 6 point likert type scale ranging from 0 to 5 where 0 is disagree strongly and 5 is agree strongly.

\section{The Multidimensional Scale of Perceived Social Support:}

The multidimensional scale of perceived social support was used to measure the social support provided to the individual after he/she has faced victimization at the hands of their peers. It is created by Zimet GD, Dahlem NW, Zimet SG, Farley GK. The Multidimensional Scale of Perceived Social Support (MSPSS) is a brief research tool designed to measure perceptions of support from 3 sources: Family, Friends, and a Significant Other. The scale is comprised of a total of 12 items, with 4 items for each subscale. Cronbach alpha level of .88 for the scale. The scale is a likert type scale ranging from 1 to 7 where 1 being very strongly disagree to 7 being very strongly agree.

\section{Procedure}

The participants taking part in the study were personally contacted to participate in the study. Rapport was established with them to make them comfortable in the setting. They were given the stated questionnaires to solve. Standard instructions were written on the questionnaires. In case of any difficulty they were encouraged to ask questions. After finishing the solving part 
of the questions, the participants were asked to return the set of questionnaires. The participants were debriefed about the entire study after their participation was over.

\section{RESULTS AND DISCUSSION}

The descriptive analysis of the data is stated below.

Table 1 Mean and Standard Deviation for the three variables.

\begin{tabular}{|l|c|c|c|}
\hline Peer Victimization & 17.85 & 4.41 & 100 \\
\hline $\begin{array}{l}\text { Personal Growth } \\
\text { Initiative }\end{array}$ & 56.26 & 10.84 & 100 \\
\hline $\begin{array}{l}\text { Perceived Social } \\
\text { Support }\end{array}$ & 64.06 & 9.86 & 100 \\
\hline
\end{tabular}

With reference to Table 1, the means for the variables Peer Victimization, Personal Growth Initiative and Perceived Social Support are 17.85, 56.26 and 64.06 respectively. Also, the standard deviation for the variables was found to be 4.41, 10.84 and 9.86 respectively. As the data was analyzed with the help of Pearson's correlation method, the correlation was found out between the variables I.e. Peer Victimization and Personal Growth Initiative and Perceived Social Support.

Table 2 The correlation matrix for Peer victimization and Personal Growth Initiative.

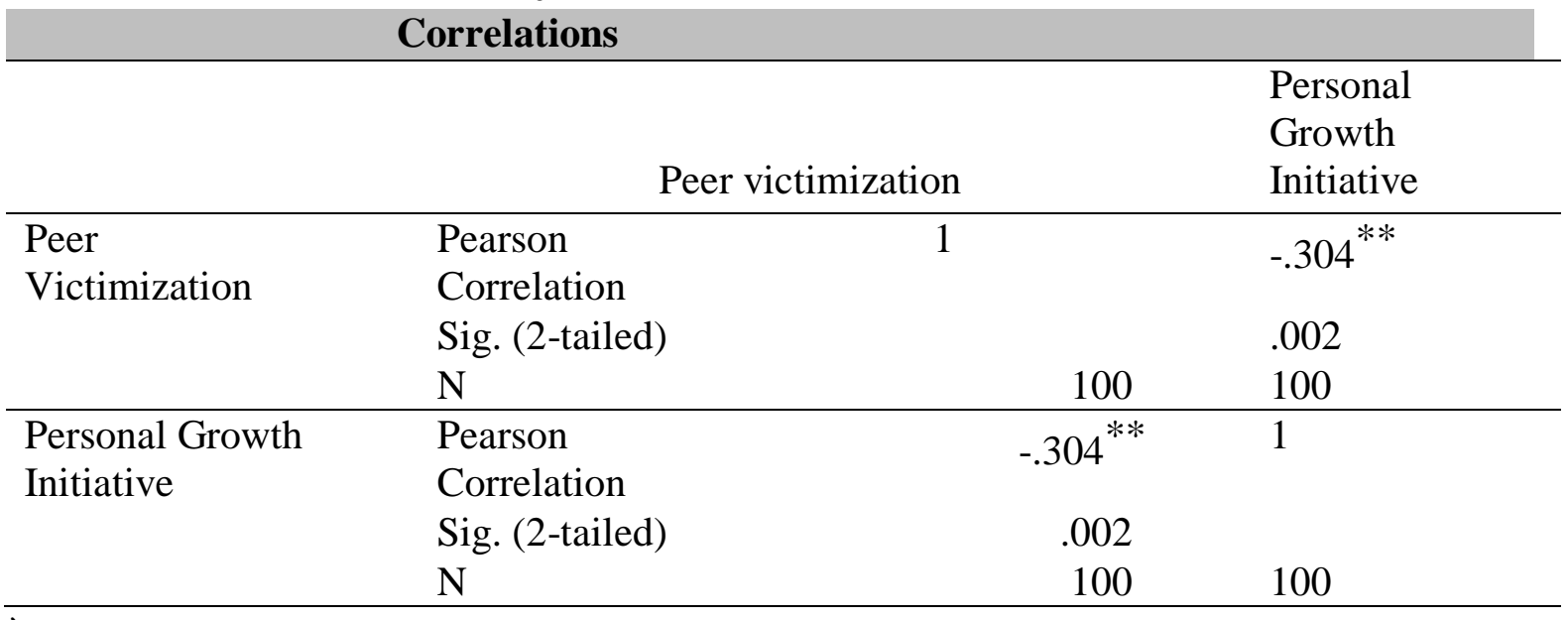

The interrelationship observed between Peer Victimization and Personal Growth Initiative was established to be -0.31 . Although, the correlation obtained is weak, statistical investigation revealed a significant negative relationship between the variables. $(r=-0.304, \mathrm{p}<$ $0.01)$.

Table 3 The correlation matrix for Personal Growth Initiative and Perceived Social Support.

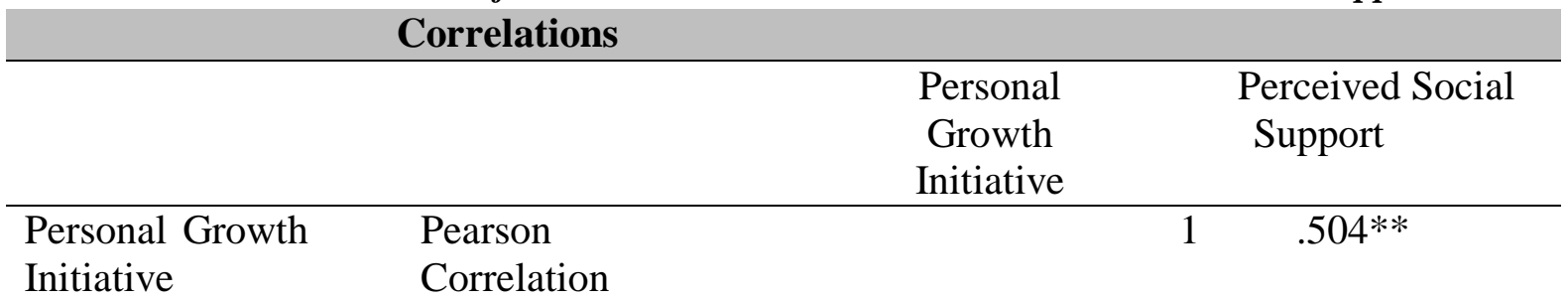

(c) The International Journal of Indian Psychology, ISSN 2348-5396 (e)| ISSN: 2349-3429 (p) | 109 


\begin{tabular}{|c|c|c|c|}
\hline \multicolumn{4}{|c|}{ Correlations } \\
\hline & $\begin{array}{l}\text { Sig. (2- } \\
\text { tailed) }\end{array}$ & & .000 \\
\hline & $\mathrm{N}$ & 100 & 100 \\
\hline \multirow{4}{*}{$\begin{array}{l}\text { Perceived Social } \\
\text { Support }\end{array}$} & Pearson & $.504^{* *}$ & 1 \\
\hline & Correlation & & \\
\hline & $\begin{array}{l}\text { Sig. (2- } \\
\text { tailed) }\end{array}$ & .000 & \\
\hline & $\mathrm{N}$ & 100 & 100 \\
\hline
\end{tabular}

With reference to table 3, it was detected that the relationship between Personal Growth Initiative and Perceived Social Support was 0.50. However, the correlation obtained is moderate it was observed to be a significant positive relationship between the variables. $(r=0.504, \mathrm{p}<0.01)$.

Table 4 The correlation matrix for Peer Victimization and Perceived Social Support.

\begin{tabular}{|c|c|c|c|}
\hline \multicolumn{3}{|c|}{ Correlations } & \multirow[b]{2}{*}{$\begin{array}{l}\text { Perceived } \\
\text { Social } \\
\text { Support }\end{array}$} \\
\hline & & Peer Victimization & \\
\hline Peer & Pearson & 1 & -.189 \\
\hline \multirow[t]{3}{*}{ Victimization } & Correlation & & \\
\hline & Sig. (2-tailed) & & .060 \\
\hline & $\mathrm{N}$ & 100 & 100 \\
\hline Perceived & Pearson & -.189 & 1 \\
\hline \multirow[t]{3}{*}{ Social Support } & Correlation & & \\
\hline & Sig. (2-tailed) & .060 & \\
\hline & $\mathrm{N}$ & 100 & 100 \\
\hline
\end{tabular}

The interrelationship observed between Peer Victimization and Perceived Social Support was -0.18. The correlation procured is negligible. However, further statistical inquiry did not report a significant relationship between the variables. $(r=-0.189, \mathrm{n} . \mathrm{s})$.

The correlation obtained for Peer Victimization and Personal Growth Initiative and that for Peer Victimization and Perceived Social Support was constituted to be abrogatory or negative. This negative correlation between the variables states that the variables are inversely correlated. Which means that if the value of one variable increases, the value of the other variable is impelled to decrease.

Also, the values of -0.304 and -0.189 lie very close to the value of 0 . This may also mean that the predictor variable does correlate at one place staunchly because statistical analysis divulged a significant relationship, but not at other times.

The first research question dealt with the relationship between Peer Victimization and Personal Growth Initiative among adolescents. There was a relationship found between the 
aforementioned variables. However, the results reported a correlation of only -0.31 between Peer Victimization and Personal Growth Initiative which as mentioned before was found to be significant at 0.01 level. As these circumstantial variables have not been studied before, there is an absence of researches to support the data calculated in this study.

Second research question concerns whether there was any relationship between Personal Growth Initiative and Perceived Social Support among adolescents. When the two scales were compared and correlated, there was a significant positive correlation found between the two variables. The significance level was found at 0.01 level $(\mathrm{p}<0.01)$. This indicates that, there were robust interconnections. It also designated that, if one of the variable increases, then the other one is bound to increase and vice versa. The co-efficient value procured was 0.50 which indicated a moderate positive correlation between the two variables. It is also evincive that the two variables I.e. Personal Growth Initiative and Perceived Social Support conduce that higher the personal growth initiative of an individual, higher will be the perceived social support and vice versa.

The third research question concerns whether there was any relationship between Peer Victimization and Perceived Social Support among adolescents. The correlation was found to be -0.18 between the variables. The correlation was found to be imperceptible as the value of -0.18 is very close to zero. Further statistical analysis avowed that there was no significant relationship found between the variables.

The topic of this particular study has not been studied extensively before. Because of this there tends to be certain limitations to the study. This study lacks enough empirical support. There is a demand to have these particular variables studied more and make further additions to this particular topic. This study immensely lacks the evidence that such research has taken place in the past. And hence, more factual researches have to be conducted in this particular field. However, this study might act as a stepping stone towards the instrumentation of researches in this field.

\section{CONCLUSION}

Thus, through this present study we can conclude that there was a significant negative relationship observed between Peer Victimization and Personal Growth Initiative. I.e. if peer victimization increases, personal growth initiative will decrease and vice versa. There was a significant positive relationship observed between Personal Growth Initiative and Perceived Social Support which means that if personal growth initiative increases, perceived social support also increases and vice versa. And a negative relation was procured between Peer Victimization and Perceived Social Support which indicates that if peer victimization increases, perceived social support will decrease and vice versa.

\section{Significance of the Study}

As there is now a correlation established within the variables however weak it might be, this study needs to be further empirically sound and pragmatic. Implications of this study may 
include forming intervention strategies for the individuals faced with peer victimization. They may be helped by providing them with social support and also providing them with a direction towards self- change. This study can be taken one step further by conducting a multiple regression analyses to predict the value of a variable based on the value of two or more other variables. Also, it can further be comprehended with the help of a t-test to find out the effects of peer victimization on personal growth initiative and perceived social support. Also, as the population recruited for this study was adolescents, this study can be taken further to study the peer victimization that takes place in workplace in addition to this it can also be studied.

As all the scales used for this particular study encompass various subscales as mentioned above, a multiple regression could be entrenched to find out how significantly can one subscale can predict the other. This can be done for all the sub-scales. The paucity of demographics used in this study had rendered its scope to be limited which can be further increased to obtain a study with lessened inherent limitations when it comes to demographics.

\section{Limitations}

The study conducted lacks enough sample size which might result in the study not being generalized to rather larger population. The sample was taken from the city of Mumbai only which might also serve as a limitation. The data collected and the conclusions drawn cannot be generalized to a large population, however, there is scope for further research.

\section{REFERENCE}

Benoît Galand, V. H. (2012). Peer victimization and school disaffection: The moderation effect of social support and the mediation effect of depression. British journal of educational psychology, 569-590.

Brown, B. B., (1990). Peer groups and peer cultures. Feldman \& Elliott 1990, pp. 171-96.

Hobfoll, S. E., Vaux, A. (1993). Social support: Social resources and social context. In L. Golberger, S. Breznitz (Eds.), Theoretical and clinical aspects, 685-705. New York: Free Press.

Hogue A, Steinberg L. (1995). Homophily of internalized distress in adolescent peer groups. Developmental Psychology. 31:897-906.

Larson R, Richards M. H., (1991). Daily companionship in late childhood and early adolescence: changing developmental contexts. Child Development. 62:284-300.

Martin, H. (2009). Personal growth initiative as a moderator of expressive writing tasks: test of a matching hypothesis. M.A. Thesis, Faculty of the Graduate School of the University of Maryland.

Megan M. Muchicko, A. L. (2014). Peer victimization, social support and leisure-time physical activity in transgender and cisgender individuals. Leisure/Loisir, Vol. 38, Nos. 3-4, 295-308.

Olweus, D. Bullying at School. Oxford, UK: Blackwell 1993.

Prahbhjot Malhi, B. B. (2015). Peer Victimization Among Adolescents: Relational and Physical Aggression in Indian Schools. Psychological Studies . 
Robitschek, C. \&Kashubeck, S. (1999). A structural model of parental alcoholism, family functioning, and psychological health: The mediating effects of hardiness and personal growth orientation. Journal of Counselling Psychology, 46,159-172.

Robitschek, C. (1997). Life/Career Renewal: An Intervention for Vocational and Other Life Transitions. Journal of Career Development, 24(2), 133-46.

Robitschek, C., and Ashton et.al. (2009). Development of the personal growth initiative scale-II. Poster presented at the First World Congress on Positive Psychology, Philadelphia, Pennsylvania, U.S.A. Journal of Career Development, 24(2), 133-46.

Yadav, S. (2009). Perceived social support, hope, and quality of life of persons living with HIV/AIDS: a case study from Nepal.

\section{Acknowledgements}

The authors profoundly appreciate all the people who have successfully contributed in ensuring this paper is in place. Their contributions are acknowledged however their names cannot be able to be mentioned.

\section{Conflict of Interest}

The authors colorfully declare this paper to bear not conflict of interests

How to cite this article: Pol, S \& Chandani, J (2018). Relationship between Peer Victimization, Personal Growth Initiative and Perceived Social Support. International Journal of Indian Psychology, 6(3), 104-113. DIP:18.01.051/20180603, DOI:10.25215/0603.051 